Marquette University

e-Publications@Marquette

Biological Sciences Faculty Research and

Publications

Biological Sciences, Department of

3-1-2019

Connectivity Explains Local Ant Community Structure in A

Neotropical Forest Canopy: A Large-Scale Experimental Approach

Benjamin J. Adams

Stefan A. Schnitzer

Stephen P. Yanoviak

Follow this and additional works at: https://epublications.marquette.edu/bio_fac

Part of the Biology Commons 


\title{
Connectivity explains local ant community structure in a Neotropical forest canopy: a large-scale experimental approach
}

\author{
Benjamin J. Adams, ${ }^{1,2}$ Stefan A. Schnitzer,,${ }^{3,4}$ and Stephen P. Yanoviak ${ }^{2,4,5}$ \\ ${ }^{1}$ Urban Nature Research Center, Natural History Museum of Los Angeles County, Los Angeles, California 90007 USA \\ ${ }^{2}$ Department of Biology, University of Louisville, Louisville, Kentucky 40292 USA \\ ${ }^{3}$ Department of Biological Sciences, Marquette University, Milwaukee, Wisconsin 53201 USA \\ ${ }^{4}$ Smithsonian Tropical Research Institute, Balboa, Republic of Panama
}

Citation: Adams, B. J., S. A. Schnitzer, and S. P. Yanoviak. 2019. Connectivity explains local ant community structure in a Neotropical forest canopy: a large-scale experimental approach. Ecology 100(6):e02673. 10.1002/ecy.2673

Abstract. Understanding how habitat structure and resource availability affect local species distributions is a key goal of community ecology. Where habitats occur as a mosaic, variation in connectivity among patches influences both local species richness and composition, and connectivity is a key conservation concern in fragmented landscapes. Similarly, availability of limiting resources frequently determines species coexistence or exclusion. For primarily cursorial arthropods like ants, gaps between neighboring trees are a significant barrier to movement through the forest canopy. Competition for limited resources such as nest sites also promotes antagonistic interactions. Lianas (woody vines) connect normally isolated neighboring tree crowns and often have hollow stems inhabited by ants. We used two large-scale lianaremoval experiments to determine how connectivity and nest site availability provided by lianas affect arboreal ant species richness, species composition, and $\beta$-diversity in a lowland tropical forest in Panama. Removing lianas from a tree crown reduced ant species richness up to $35 \%$, and disproportionately affected species that require large foraging areas. Adding artificial connectivity to trees mitigated the effects of liana removal. Ant colonization of artificial nests was higher ( $73 \%$ occupied) in trees without lianas vs. trees with lianas ( $28 \%$ occupied). However, artificial nests typically were colonized by existing polydomous, resident ant species. As a result, nest addition did not affect ant community structure. Collectively, these results indicate that lianas are important to the maintenance of arboreal ant diversity specifically by providing connectivity among neighboring tree crowns. Anticipated increases in liana abundance in this forest could increase the local (tree-level) species richness of arboreal ants, with a compositional bias toward elevating the density of broad-ranging specialist predators.

Key words: arboreal; Dipteryx oleifera; Formicidae; lianas; Panama; species-area relationship.

\section{INTRODUCTION}

A fundamental goal of community ecology is to understand the mechanisms underlying local species richness and composition (e.g., Agrawal et al. 2007). Because of their discrete boundaries, insular habitats have been particularly important in the development of community assembly theory (e.g., species-area curves, the theory of island biogeography, and metapopulation theory; Preston 1962, MacArthur and Wilson 1967, Hanski and Gilpin 1991). In general, dispersal limitation, habitat filters, and species interactions determine local community assembly and species composition in ecological time (Hanski and Gilpin 1991). Changes to habitat boundaries via connecting normally isolated habitats (Rahel 2007) or

Manuscript received 5 October 2018; revised 14 January 2019; accepted 4 February 2019. Corresponding Editor: David Holway.

${ }^{5}$ Corresponding Author. E-mail: steve.yanoviak@louisville.edu fragmenting continuous landscapes (Fahrig 2003) can directly influence all of these processes by either impeding or facilitating the flow of resources or organisms (Taylor et al. 1993). However, experimental manipulations of habitat boundaries are few and often focus on relatively simple systems (Huffaker 1958, Gonzalez et al. 1998; but see Tewksbury et al. 2002) or fragmentation (Laurance et al. 1997, Ewers 2011).

Habitat complexity (Tews et al. 2004) and resource availability (Tilman 1982) also determine local species richness and composition. More complex habitats can facilitate coexistence between predator and prey populations (Huffaker 1958), and structural heterogeneity enhances local diversity via increased niche availability (MacArthur and MacArthur 1961). Likewise, shared resources affect local species richness and composition via interspecific competition (Levins et al. 1973, Tilman and Pacala 1993). Physical niches used for nesting or shelter typically increase with habitat complexity but can be a limiting resource in isolated habitats like tidal pools 
(Metaxas and Scheibling 1993) and tree crowns (Ribas et al. 2003).

Trees function as ecological islands for some arboreal organisms (Southwood and Kennedy 1983, Adams et al. 2017, Patiño et al. 2018). Although forest canopies superficially resemble continuous landscapes, individual tree crowns typically are isolated in space due to crown shyness (i.e., well-defined gaps existing between neighboring crowns; Ng 1977, Putz et al. 1984). Such intercrown gaps limit the movement of some organisms, thus producing a series of species assemblages that are spatially proximate, yet quite isolated (Emmons and Gentry 1983, Southwood and Kennedy 1983, Yanoviak 2015). Consequently, local community structure within a forest canopy likely is shaped by connections among neighboring tree crowns and local (within-tree) resource availability (Ribas et al. 2003, Yanoviak and Schnitzer 2013) as forest canopies represent a naturally fragmented landscape.

Lianas (woody vines) are a common and conspicuous component of tropical forest canopies (Pérez-Salicrup et al. 2001, Ingwell et al. 2010, Schnitzer et al. 2012). Individual lianas grow within and between crowns of multiple trees (Putz 1984b), thus providing important physical habitat connections for arboreal animals (Yanoviak 2015). Lianas also can provide nest sites and other resources for forest animals (Blüthgen and Fiedler 2002, Tanaka et al. 2010, Yanoviak and Schnitzer 2013, Yanoviak 2015, Adams et al. 2017). However, not every tree has lianas, and many trees shed lianas during their lifetimes (Putz 1984a, Phillips et al. 2005, Ingwell et al. 2010). Thus, intertree connectivity and resources provided by lianas are variable in space and time. As a result, tropical forest canopies provide a unique opportunity to explore the ecological importance of variable habitat boundaries (via changes in connectivity) and resource availability in a system that exhibits conspicuous natural variation in these characteristics. Moreover, total liana abundance is increasing in tropical forests around the world (Schnitzer 2015), and the effects of this change on arboreal animal communities remain unknown (Yanoviak 2015).

Lianas have a particularly strong influence on the local distribution of canopy insects, including arboreal ants (Yanoviak 2015, Adams et al. 2017). Ants are an ecologically important taxon in tropical forest canopies (Rico-Gray and Oliveira 2007); they also are taxonomically well resolved and easy to observe and collect, making them ideal candidates for ecological studies. Arboreal ants require physical connections to move through the forest canopy. In the absence of lianas, arboreal ant assemblages have lower average species richness and lack species having wide-ranging foraging habits (Adams et al. 2017). Ant species richness also increases predictably with tree size in trees lacking lianas, but is unaffected by tree size in trees with lianas (Adams et al. 2017). Together, these observations suggest that the presence of lianas shapes arboreal ant community structure by connecting otherwise isolated tree crowns.
Apart from connectivity, lianas are an important source of nest sites for arboreal ants. Nest sites are a limiting resource for ants in some settings (Philpott and Foster 2005, Frederickson 2006, Powell et al. 2011), and arboreal ants commonly occupy the living and dead hollow stems that are characteristic of many liana species (Rico-Gray and Oliveira 2007, Philpott 2010, Yanoviak 2015). Given that lianas represent $2 \%$ of tropical forest biomass but $12 \%$ of total dead wood volume for debris 2-10 cm in diameter (Gora et al. 2019), lianas likely are disproportionately important sources of twig nests for ants. However, there are no explicit tests of how lianas influence nest site availability and, consequently, ant distributions in arboreal systems.

Here, we experimentally investigated how lianas affect arboreal ant community structure (species richness, species composition, and $\beta$-diversity) at local scales (i.e., among individual tree crowns). Given that ant assemblages in liana-free trees follow patterns of insular communities (Adams et al. 2017), and that nest sites likely are a limiting resource for arboreal ants (Philpott and Foster 2005), we focused on two mechanistic questions. First, does variation in connectivity shape local ant community structure, as suggested by previous observational work (Yanoviak 2015, Adams et al. 2017)? We predicted that if connectivity plays a major role in determining local ant species richness and composition, removal of connective structures (e.g., lianas) would reduce ant species richness with particularly strong effects on ants that require large foraging areas. The addition of artificial connective structures (e.g., ropes) should mitigate the impacts of liana removal. Second, do lianas affect ant community structure via nest site availability (Philpott and Foster 2005, Powell et al. 2011)? If lianas primarily influence local ant communities by providing ideal nest conditions, the addition of artificial nests in trees without lianas should increase local ant species richness. Additionally, ants should more frequently occupy artificial nests when lianas are not present in a tree. We employed two large-scale experimental approaches to answer these questions in a lowland forest of Panama.

\section{Materials And Methods}

\section{Study site}

We conducted fieldwork in the Barro Colorado Nature Monument (BCNM), Panama $\left(09.15^{\circ} \mathrm{N}\right.$, $79.85^{\circ} \mathrm{W}$ ), from 2009 to 2017 . Individual field projects spanned 3-9 yr. Both the plants and the ants in the $\mathrm{BCNM}$ are relatively well documented, making this an ideal location for community-level manipulations (Condit 1995, Schnitzer 2012, Adams et al. 2017). Additional details about the BCNM are provided elsewhere (e.g., Leigh et al. 1996).

We explored the role of lianas in structuring arboreal ant communities via two large experiments. The first was 
a manipulation of liana abundance and connectivity in sixteen $80 \times 80 \mathrm{~m}$ plots on Gigante Peninsula, half of which had all lianas removed in 2011 (hereafter, the "Plot" experiment; van der Heijden et al. 2015, Martínez-Izquierdo et al. 2016, Garcia-Leon et al. 2018). Second, we manipulated connectivity and nest resources in two factorial experiments comprising 80 Dipteryx oleifera trees on Barro Colorado Island and Gigante Peninsula (hereafter, the "Dipteryx" experiments). We conducted the Dipteryx experiments in individual trees (rather than plots) to imitate more closely the localized disturbance created by natural liana turnover in forests (vs. plot-scale removals, which superficially are more similar to hurricane damage).

We specifically focused on a single tree species for the Dipteryx experiments to avoid any potentially confounding tree-species effects on arboreal ant community structure (Ribas et al. 2003, Adams et al. 2017). Preliminary surveys for this project and from related studies (Yanoviak and Kaspari 2000, Adams et al. 2017) showed that $D$. oleifera has high ant species richness relative to other common canopy tree species in the BCNM. Also, the dense wood and growth form of D. oleifera provide a wide range of climbable tree sizes $(15-115 \mathrm{~cm}$ diameter at breast height $[\mathrm{DBH}]$ in this project) and a wide range of liana infestation (from zero to thousands of liana stems per crown), thus making the study logistically feasible.

\section{Ant surveys}

We surveyed arboreal ants during the early wet season (May-August) of each year between 09:00 and 16:00. We accessed tree crowns using the single rope climbing technique (Perry 1978) and surveyed the arboreal ant communities by baiting and hand collecting. We conducted 659 surveys in 121 individual trees (representing 39 genera) across 9 yr (2009-2017) in the Plot experiment. We conducted an additional 275 surveys in 80 D. oleifera trees in the Dipteryx experiments.

We recorded date, time of day, and air temperature at the beginning of each survey. We calculated the basal area of each tree $\left(\mathrm{BA}=\pi(\mathrm{DBH} / 2)^{2}\right)$, which served as a proxy for arboreal habitat size (i.e., crown area; O'Brien et al. 1995). We collected ants using a combination of chicken or tuna mixed with honey as bait. We placed baits on surfaces of branches and liana stems that were accessible from the central fork of the tree and collected workers of all ants observed in the tree for $1 \mathrm{~h}$. Additional details regarding ant survey methods are provided elsewhere (Adams et al. 2017). We stored ants in 95\% ethanol and identified them in the lab using online and published keys (e.g., Ward 1989, Longino 2007). Taxonomists confirmed the species identity of reference specimens, and vouchers were deposited at the University of Louisville, the United States National Museum, the Smithsonian Tropical Research Institute, and the University of Panama.

\section{Liana-removal plot experiment}

We used ant survey data from liana removal and control plots to determine how liana removal influenced ant species richness, species composition, and $\beta$-diversity at the scale of both individual tree crowns and the whole plot. Each plot contained ca. 3,600 tree stems $\geq 1 \mathrm{~cm}$ diameter (Reid et al. 2015) and, prior to liana removal, ca. $86 \%$ of trees $\geq 10 \mathrm{~cm}$ DBH had lianas in their crowns (van der Heijden et al. 2015). Ant collections were made in at least three canopy trees in each of the 16 plots in 2009 and 2010 to characterize the pretreatment arboreal ant communities. Lianas were then cut at ground level in 2011 and allowed to rot and fall from the trees naturally; all new liana growth was cut every 3 months for the duration of the experiment (van der Heijden et al. 2015, Garcia-Leon et al. 2018). This experimental manipulation removed ca. 2,000 liana stems $\geq 1 \mathrm{~cm}$ diameter in each of the removal plots (Reid et al. 2015). Ants in each canopy tree were resurveyed annually until 2017 (excluding 2016) as described above to determine if liana removal affected the ant communities. New trees were added to each plot in 2014 to bring the average number of trees per plot to seven (range $=5-8$ trees per plot).

We used a repeated-measures linear model ( $\mathrm{R}$ package nlme) to determine if average arboreal ant species richness in individual tree crowns $\left(S_{\text {crown }}\right)$ and the proportional change in ant species richness $\left(\Delta S_{\text {crown }}\right)$ were affected by liana removal during the $9 \mathrm{yr}$ of this study. $\Delta S_{\text {crown }}$ for each tree was calculated as the difference in ant species richness in each year of the experiment from the species richness recorded in the pretreatment survey, divided by the pretreatment species richness value (i.e., $\left.\Delta S_{\text {crown }}=\left[S_{\text {crown,year }}-S_{\text {crown,pre }}\right] S_{\text {crown,pre }}\right)$. Individual trees served as the repeated-measure grouping factor across years, and only those trees with data from all annual surveys were included in the $\Delta S_{\text {crown }}$ analysis (i.e., trees added in 2014 were not included in tests of $\Delta S_{\text {crown }}$ because they lacked pretreatment surveys). We originally included plot as a random grouping factor and air temperature as a covariate in both models, but dropped these variables following nested model reduction using differences in AIC values and likelihood ratio tests (Bolker et al. 2009).

We also calculated mean ant species richness at the plot-level $\left(S_{\text {plot }}\right)$. The number of trees surveyed varied among plots and years (range: 3-8 trees $\operatorname{plot}^{-1} \cdot \mathrm{yr}^{-1}$ ), and ant species richness is incidence-based. Thus, we estimated plotwide ant species richness using samplebased rarefaction and limited the data to the minimum number of trees surveyed (three trees; Colwell et al. 2012). These rarefied species richness values served as the response variable in a repeated-measures linear model testing the hypothesis that liana removal negatively affected plotwide ant species richness. As with $\Delta S_{\text {crown }}$ described above, we used the proportional change in plot-level ant species richness $\left(\Delta S_{\text {plot }}\right)$ as the response variable for a second repeated-measures linear 
model. Individual plots were treated as the repeatedmeasure grouping factor across years for both models. The $\Delta S_{\text {plot }}$ analysis used rarefied ant species richness values from all tree surveys, including those that were added after the start of the experiment.

We used PERMANOVA (Anderson et al. 2008) to determine if ant species composition changed within individual tree crowns, and across the plots, as a result of liana removal over the course of the 9-yr study. Because ants are social organisms, abundance data are only ecologically relevant when measured as nest density; thus, we used the incidence-based Jaccard index for species composition and similarity analyses (Gotelli et al. 2011). Time, treatment, and their interaction served as fixed effects for these analyses. $P$-values were computed using 9,999 permutations of the residuals. We visualized the effects of liana removal on species composition using nonmetric multidimensional scaling (NMDS, 9,999 permutations). We also used indicator species analyses to determine which ant species contributed to differences detected between removal and control treatments (de Cáceres et al. 2010).

We tested for differences in $\beta$-diversity resulting from liana removal with PERMDISP (Anderson et al. 2008). PERMDISP uses fixed factors to define sample groups in a data set, then compares the average distance of individual samples within a sample group to a group-defined centroid in multivariate space created from a similarity matrix. A sample group with higher $\beta$-diversity (i.e., higher variability in species composition among individual samples) will have a larger average distance from the group centroid (Anderson et al. 2011). $P$-values for this test are computed using permutations of the leastsquared residuals. We used the same Jaccard similarity matrices and models used in the PERMANOVA analyses and 9,999 permutations of the least-squared residuals to calculate $P$-values.

\section{Connectivity manipulations in Dipteryx trees}

The first of the two Dipteryx experiments was a twoby-two factorial (Appendix S1: Fig. S1) testing whether ant species richness, composition, and $\beta$-diversity are affected by intertree connectivity. At the beginning of this experiment, each tree contained at least one liana in its crown that connected it to at least one nearby canopy tree. The experimental design included a liana-removal treatment and a rope addition treatment. For lianaremoval treatments, liana stems were cut at ground level and allowed to fall out of the tree as described above (Reid et al. 2015, Martínez-Izquierdo et al. 2016). The rope addition treatment consisted of a single 10-14 mm diameter climbing rope tied to the central axis of the tree and to the nearest canopy tree, thereby connecting the two tree crowns. These connections were typically 20 $40 \mathrm{~m}$ in total length, and arboreal ants readily used the climbing ropes to move between trees. Each of the four experimental treatments included $10 \mathrm{D}$. oleifera trees for a total of 40 trees. We surveyed the arboreal ants in each tree prior to experimental manipulations to provide pretreatment controls.

We used the same repeated-measures linear model approaches used for individual trees in the Plot experiment to determine if average arboreal ant species richness $\left(S_{\text {connectivity }}\right)$ and the average change in ant species richness over time ( $\left.\Delta S_{\text {connectivity }}\right)$ differed among the four treatments in the rope addition experiment. Because there were four treatments in this experiment, we used a post hoc Tukey's HSD to compare groups within treatment and year when significant differences were detected. We also used $t$-tests to determine if average ant species richness $\left(S_{\text {connectivity }}\right)$ differed between the pretreatment controls and the final survey (Year 3).

We used PERMANOVA and PERMDISP to determine if liana removal and rope additions changed arboreal ant species composition and $\beta$-diversity. We used Jaccard distances to create the similarity matrix, and we treated time, treatment, and their interaction as fixed effects in models. $P$-values were calculated using 9,999 permutations of the residuals for PERMANOVA, and using least-squared residuals for PERMDISP. Differences in species composition among treatments were visualized using NMDS (9,999 permutations) and ant species associated with specific treatments were identified using indicator species analysis.

\section{Species-area relationship}

We used regression to test for a linear relationship between tree size (basal area) and arboreal ant species richness in the initial and final surveys of the lianaremoval treatments in both the Plot and Dipteryx experiments described above. The goal of this analysis was to determine if a positive species-area relationship occurred following liana removal, as suggested by our prior studies of this system (Adams et al. 2017). The analysis only included trees in the Plot experiment for which we had both pretreatment and 2017 ant survey data (i.e., the final survey).

\section{Artificial nest additions in Dipteryx trees}

The second of the two Dipteryx experiments was a factorial test (Appendix S1: Fig. S2) designed to determine (1) if colonization of artificial nests differs between trees with and without lianas; and (2) if nest addition affects arboreal ant species richness, species composition, and $\beta$-diversity in trees with and without lianas. Artificial nests constructed of native or exotic wood are readily occupied by most arboreal ant genera in Neotropical forests (Philpott and Foster 2005). In contrast to the previous plot and rope experiments, half of the trees selected for this experiment naturally did not have lianas in their crowns at the start of the experiment; the other half contained at least one liana that connected the tree crown to at least one other canopy tree. 
We added 15 artificial nests to each tree in the nest addition treatments (e.g., trees with and without lianas, Appendix S1: Fig. S2). An artificial nest consisted of one $5 \times 5 \times 20 \mathrm{~cm}$ block of native hardwood (Bombacopsis quinata) containing a $2 \times 10 \mathrm{~cm}$ cylindrical cavity with a $0.67 \mathrm{~cm}$ diameter entrance hole (Appendix S1: Fig. S3). We secured the artificial nests to branches or lianas near the central axis of the tree. Individual nests were separated from each other by $\geq 1 \mathrm{~m}$. Nests were secured to the trees using a metal wire or nylon cord that was strung through a small hole $(0.67 \mathrm{~cm}$ diameter $)$ drilled through the wooden block on the end opposite from the nest cavity entrance hole (Appendix S1: Fig. S3).

We used a $t$-test to determine if the proportion (\%) of nests occupied differed between trees with and without lianas in the final survey year. We used the same analyses described in the liana-removal experiment to analyze differences in species richness, species composition, and $\beta$-diversity between the nest site treatments over time.

We originally included five trees in each plot in the liana-removal plot experiments and 10 trees in each treatment of both the connectivity manipulations and nest addition factorial experiments. Because of tree falls or hazards like wasp colonization, each tree was not surveyed every year. Ultimately, we included a minimum of three trees per plot per year (mean $=5.4 \pm 1.4$ trees) in the plot experiment and nine trees per treatment per year $(9.8 \pm 0.4$ trees $)$ in the connectivity and nest addition experiments. Raw species richness and tree basal area were $\log$ transformed or square-root transformed where necessary to improve normality, which was confirmed using the Shapiro-Wilk test. Proportions of nests occupied were arcsine-square-root transformed. Bonferroni-adjusted alphas were used to correct for multiple comparisons. We used the $\mathrm{R}$ statistical package version 3.5.0 (R Core Team 2018) for all analyses except PERMANOVA and PERMDISP, which were conducted with PRIMER version 6.1.18 (Clarke and Gorley 2006) and the PERMANOVA+ package 1.0.8 (Anderson et al. 2008).

\section{REsUlts}

All 974 surveys were completed under sunny to partly cloudy conditions. Mean $( \pm \mathrm{SD})$ air temperature was $29.3^{\circ} \pm 1.7^{\circ} \mathrm{C}$ (range: $24.4-35.8^{\circ} \mathrm{C}$ ) during collections, and average tree size (as DBH) was $58.4 \pm 21.6 \mathrm{~cm}$ (range: 18.2-125.9 cm). Model comparison using AIC values indicated that neither of these covariates significantly differed among treatments in any of the experiments. In total, 134 species of ants were collected during this project (Appendix S2: Table S1).

\section{Liana-removal plot experiment}

Ant species richness in individual trees $\left(\Delta S_{\text {crown }}\right)$ in the liana-removal plots decreased $15 \%$ over the course of the study, whereas $\Delta S_{\text {crown }}$ in control plots where lianas were present increased ca. $45 \%$ by the end of the project (Fig. 1). Three years after removal, the relative change in ant species richness from pretreatment surveys $\left(\Delta S_{\text {crown }}\right)$ was significantly different between control and removal plots $\left(F_{1,290}=13.04, \quad P=0.0004 ; \quad F_{1,44}>5.53\right.$ and $P<0.023$ for 2014, 2015, and 2017 post hoc tests). Prior to the liana-removal treatment, average $S_{\text {crown }}( \pm \mathrm{SE})$ was higher in removal trees $(10.0 \pm 0.5$ species $)$ vs. controls ( $8.2 \pm 0.7$ species; $F_{1,50}=5.07, P=0.03$ ), but was lower in removal trees vs. control trees by the 2015 and 2017 surveys $\left(F_{1,98}>12.07, P<0.0008\right.$ for both years; Fig. 1).

After controlling for the number of trees surveyed, ant species richness per plot $\left(S_{\text {plot }}\right)$ followed similar patterns to ant species richness in individual trees. Specifically, average ant species richness declined by ca. $15 \%$ in lianaremoval plots, whereas it increased by ca. $30 \%$ in control plots over the course of the study (Fig. 2A). By the final survey, the relative change in ant species richness per plot $\left(\Delta S_{\text {plot }}\right)$ was greater in control vs. removal plots $\left(F_{1,14}=5.05, P=0.04\right)$. The average raw ant species richness per plot $\left(S_{\text {plot }}\right)$ also was greater in control plots than in removal plots in the 2017 survey $\left(F_{1,14}=6.01\right.$, $P=0.03$; Fig. 2B).

Liana removal in the Plot experiment also changed arboreal ant species composition and $\beta$-diversity. Prior to liana removal and through the 2012 surveys, ant species composition was similar between removals and controls at both the individual tree and plot levels (Pseudo- $F_{1,35}<1.04, P>0.4$ for all PERMANOVA tests; Appendix S1: Fig. S4). After 2013, ant species composition in control and removal trees diverged (Pseudo- $F_{1,35}>1.63, \quad P<0.03$ for all tests; Appendix S1: Fig. S4). Indicator species analyses revealed that several large ponerimorph ants, typically with wide-ranging foraging habits (e.g., Neoponera spp., Paraponera clavata; Beckers et al. 1989, Fewell et al. 1996), were specifically associated with the control trees. In contrast, various small Pseudomyrmex spp. were more commonly found in the removal trees (Appendix S2: Table S2). Average $( \pm \mathrm{SE}) \beta$-diversity (measured as deviation from the group centroid) was higher in the removal trees $(60.4 \pm 1.24)$ than in control trees in $2017\left(55.3 \pm 1.24 ; F_{1,44}=8.32, P=0.01\right.$; Appendix S1: Fig. S5).

\section{Connectivity manipulations in Dipteryx trees}

Removal of lianas from $D$. oleifera trees caused a $25 \%$ reduction in ant species richness, but this effect was mitigated by reconnecting trees with ropes (Fig. 3A; $\left.F_{3,113}=6.85, P=0.0003 ; \alpha=0.025\right)$. Specifically, post hoc tests of treatment within year revealed that average $\Delta S_{\text {connectivity }}$ in the liana-removal group was smaller than the other three treatments after $3 \mathrm{yr}\left(F_{3,35}=6.17\right.$, $P=0.002 ; \alpha=0.025)$. Mean $( \pm \mathrm{SE})$ ant species richness ( $S_{\text {connectivity }}$ in removal trees decreased by ca. $25 \%$ (from 

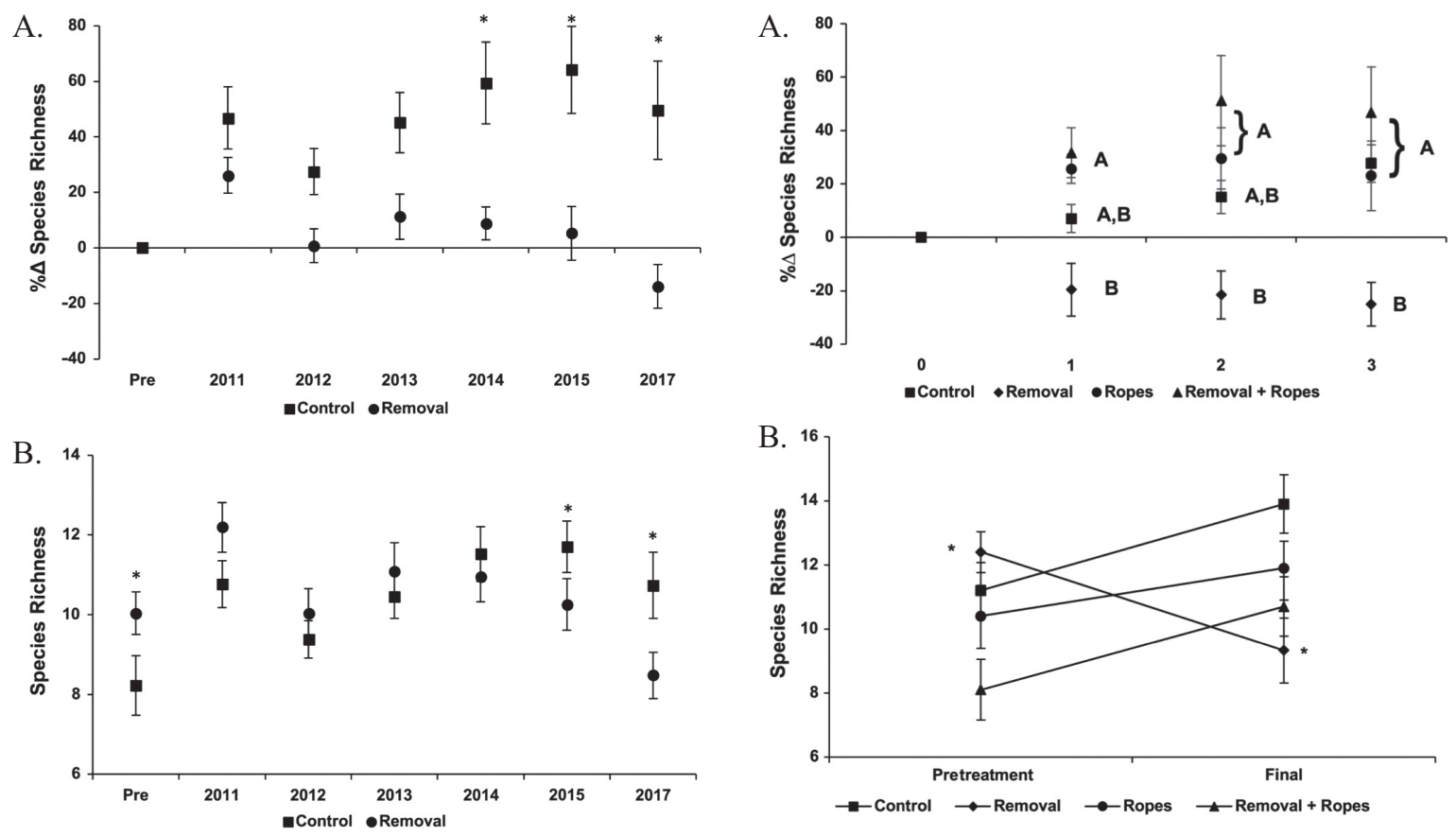

FIG. 1. (A) Average $( \pm \mathrm{SE})$ percent change in ant species richness $\left(\Delta S_{\text {crown }}\right)$, and (B) average ant species richness in individual trees $\left(S_{\text {crown }}\right)$ in the Gigante liana removal and control plots per year. Asterisks indicate significant differences between removal and control treatments within a year.
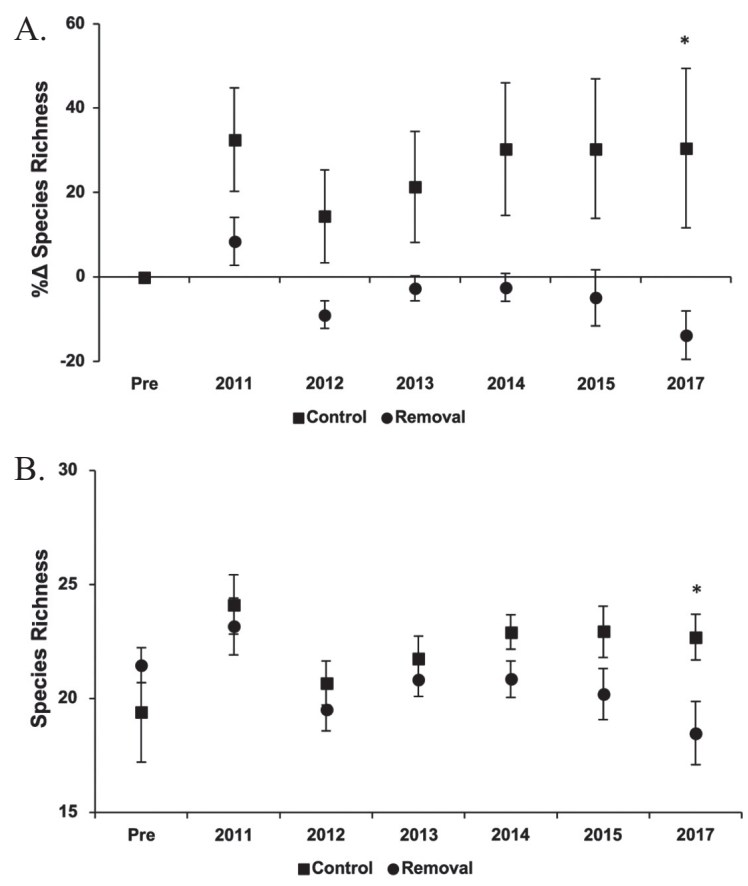

Fig. 3. (A) Average $( \pm \mathrm{SE})$ percent change in ant species richness $\left(\Delta S_{\text {connectivity }}\right)$ and (B) average ant species richness ( $S_{\text {connectivity }}$ ) following liana removal in the four connectivity treatments (see Appendix S1: Fig. S1). Annual means are calculated from $n \geq 9$ trees per treatment per year. For $\Delta S_{\text {connectivity }}$ (A), similar letters indicate treatment means do not differ within a year. For $S_{\text {connectivity }}$ (B), an asterisk indicates a significant difference between means in the initial and final surveys.

$12.4 \pm 0.6$ to $9.3 \pm 0.7)$ by the final survey $(t=3.13$, $P=0.006 ; \alpha=0.025 ;$ Fig. $3 \mathrm{~B})$. In contrast, $S_{\text {connectivity }}$ in the other three treatments did not differ from their pretreatment values $3 \mathrm{yr}$ later $(t<5.19, \quad P>0.04$; $\alpha=0.025$ for each test; Fig. 3B).

Unlike the Plot experiment, liana removal in D. oleifera trees did not change ant species composition or $\beta$-diversity. Although ant species composition differed among the four connectivity treatments (Pseudo- $F_{3,71}=1.86$, $P=0.0002$ ), pairwise tests within years revealed no differences between the pretreatment and the final surveys (Appendix S2: Table S3), indicating no change in species composition due to the experimental treatments. $\beta$-diversity did not differ among connectivity treatments in any year $\left(F_{3,36}<2.21, P>0.13\right.$ for all tests $)$.

\section{Species-area relationship}

Liana-removal resulted in a positive relationship between ant species richness and tree size $\left(F_{1,29}=6.02\right.$, $P=0.024, R^{2}=0.15$; Fig. 4). The relationship followed the power function $S_{\mathrm{a}}=10.10 \mathrm{~A}^{0.15}$ (Fig. 4) which has a lower slope but a similar intercept to previous findings for naturally liana-free trees in this forest $\left(S_{\mathrm{a}}=10.99 \mathrm{~A}^{0.25}\right.$; Adams et al. 2017). This species-area relationship was absent before liana removal $\left(F_{1,34}=0.28, \quad P=0.60\right.$; Fig. 4).

FIG. 2. (A) Average ( \pm SE) percent change in ant species richness $\left(\Delta S_{\text {plot }}\right)$, and (B) average ant species richness per plot $\left(S_{\text {plot }}\right)$ in liana removal and control plots per year. Asterisks indicate significant differences between removal and control treatments within a year. 

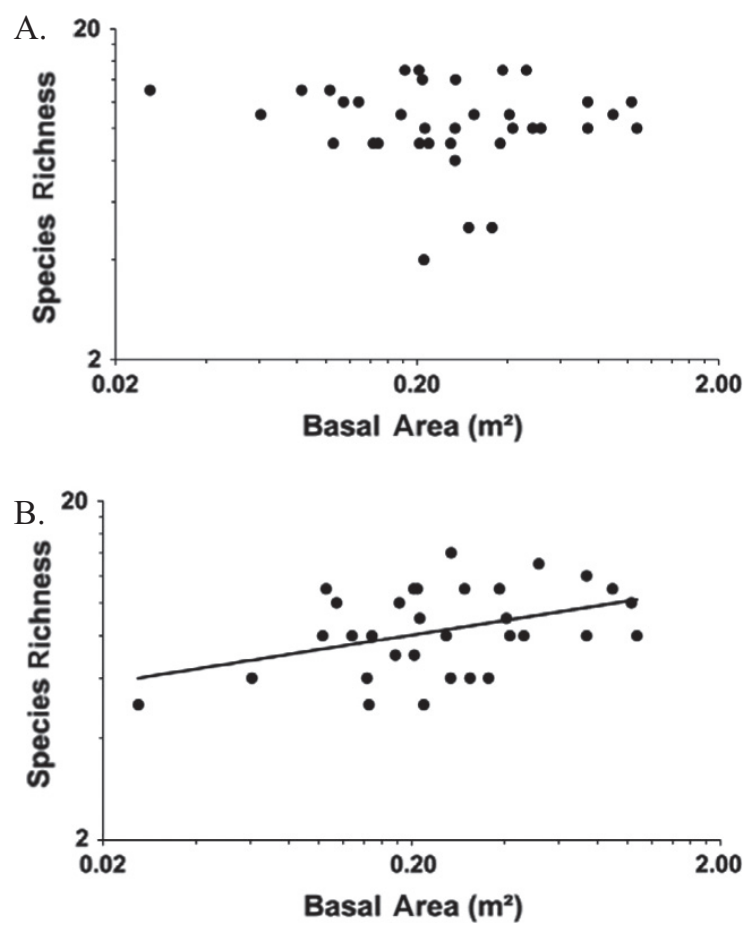

FIG. 4. (A) Ant species richness vs. tree size (as basal area) in trees prior to experimental liana removal and (B) in the final survey after liana removal.

\section{Artificial nest additions in Dipteryx trees}

Arboreal ants representing 34 species in 10 genera (ca. $25 \%$ of recorded species, Appendix S2: Table S1), occupied $73 \%$ of artificial nests in trees without lianas vs. $28 \%$ of nests in trees with lianas $\left(t_{15}=4.69, P=0.0003\right.$; Appendix S1: Fig. S6). However, the majority of the nest occupations in any given tree (and 94\% of nest occupations overall) were the result of colony expansion by resident polydomous ants (Azteca spp., Camponotus spp., Cephalotes spp., Crematogaster spp., and Dolichoderus spp.) Only 8 of the 300 artificial nests used in this experiment were colonized by ants not found in the trees during the pretreatment surveys. Thus, nest additions had no effect on the basic structure of the arboreal ant community. Specifically, species richness $\left(F_{3,73}<1.88\right.$, $P>0.14$ for treatment and year-by-treatment interaction; Appendix S1: Fig. S7), species composition (Pseudo- $F_{3,36}<1.06, P>0.33$ for treatment in both the initial and final surveys), and $\beta$-diversity $\left(F_{3,36}<2.15\right.$, $P>0.13$ in both initial and final surveys) were all unaffected by the addition of artificial nests in trees with and without lianas.

\section{Discussion}

Habitat structure is a fundamental determinant of local community structure (e.g., MacArthur and MacArthur 1961, Tews et al. 2004). In particular, physical connectivity between insular habitats promotes species coexistence and enhances local diversity in a broad range of systems, from controlled laboratory microcosms to watersheds (e.g., Huffaker 1958, Gonzalez et al. 1998, Rahel 2007). Connectivity also is considered to be an important variable in the conservation of fragmented landscapes (Bennett 1999). However, few natural systems are amenable to large-scale, replicated, manipulations of connectivity and resource availability (but see Laurance et al. 1997 and Ewers et al. 2011). Here, we show that lianas influence local arboreal ant community structure by providing connectivity among tree crowns in a tropical forest (a naturally fragmented landscape), and that ants respond to experimental changes in liana presence. Specifically, ant species richness declined significantly following liana removal, and this outcome was consistent between two experiments differing in scale. Species loss was mitigated by the addition of ropes, which functioned solely as connective structures between trees. By contrast, nest site resources provided by lianas appeared to have little effect on ant community parameters. This outcome differs from other isolated systems such as tidal pools (Metaxas and Scheibling 1993) or small coral reefs (Shulman 1984) where shelter and nest site availability affect local community structure. Collectively, these results indicate that lianas provide keystone structural components for ants (sensu Tews et al. 2004); connective corridors provided by lianas shape arboreal ant communities presumably by expanding the home range of an ant colony to multiple tree crowns.

The effects of liana removal on arboreal ants emerged slowly, given the dramatic changes in living plant biomass and canopy cover that occurred following liana cutting. We attribute this delayed effect to two factors. First, the vast majority of liana stems fell to the ground within 6 months of cutting, but some dead stems persisted in the canopy (and continued to provide connections between tree crowns) for up to ca. 18 months. Thus, although all trees were liana-free in the Plot and Dipteryx experiments by 2 yr postcutting, the effects of the manipulation on intercrown connectivity were not immediate. Second, most canopy ants appear to be rather resistant to the disturbance associated with liana removal. The clearest exceptions to this pattern were species that require large foraging areas (e.g., Camponotus sericeiventris, Neoponera spp., Paraponera clavata). The occurrence frequency of these species was rapidly and conspicuously reduced in liana-removal treatments, mirroring the compositional patterns observed in prior studies of trees that are naturally liana-free (Adams et al. 2017). Regardless, the results of this study show that experimental manipulations of liana abundance require long temporal scales to exhibit ecological effects on arboreal ants.

The tendency for ant species richness to increase over time in the control treatments of the Plot experiment also was unexpected. Although fewer total trees were surveyed 
in 2009-2011 than in subsequent years, the survey method was consistent among all years and treatments; thus, we do not attribute this pattern to a methodological artifact. The Plot experiment was established in a younger secondary forest (ca. $60 \mathrm{yr}$ old; van der Heijden et al. 2015) that is undergoing successional changes in many features, including canopy height, tree crown area, and liana and epiphyte density. The general increase in ant species richness could partly reflect these successional changes in the plant community, although this seems unlikely given the time scale of the project. Regardless, additional data collected over a longer time scale are needed to determine if the apparent trend for increasing ant species richness observed in this study is persistent and linked to forest succession, or part of a fluctuating pattern driven by climate or other factors (as suggested by the declines in species richness in 2012 and 2017).

Apart from lost connectivity, the effects of liana removal included a dramatic change in light regime (Rodriguez-Ronderos et al. 2016) that likely affected thermal microenvironments in trees and plots (Stark et al. 2017). Warmer surfaces of tree trunks and subcanopy branches could explain the increased occurrence of outer canopy ants (e.g., Pseudomyrmex spp.) in lianaremoval trees because these species have relatively high thermal tolerance (Kaspari et al. 2015). Liana removal also presumably decreased the local availability of twig nests, extrafloral nectaries, and sap-sucking insects specifically associated with lianas (Tanaka et al. 2010). Whereas the results of the artificial nest addition experiment suggest that the loss of twig nests is less important than lost connectivity, the role of changes in nutrient availability via extrafloral nectar and trophobionts (Blüthgen and Fiedler 2002, Davidson et al. 2003) following liana removal remains unknown. Regardless, the consistent loss of wide-ranging ants, the emergence of a species-area relationship in liana removal trees, and the mitigation of these effects via rope additions collectively indicate that connectivity is a major contributor to the maintenance of local arboreal ant diversity.

Differences in the importance of connectivity to arboreal ant communities between this project and similar studies (Davidson et al. 1988, Powell et al. 2011) are explained in part by differences in experimental system and canopy height. Here, we examined how ant community structure changes following liana manipulation in a high-canopy forest ( $>20 \mathrm{~m}$ tall; Putz 1984b). By contrast, Davidson et al. (1988) showed that connectivity affects binary ant occupancy of a very specialized habitat (i.e., myrmecophytic shrubs), and Powell et al. (2011) detected only a weak trend for less diverse arboreal ant communities in less connected trees of the Brazilian cerrado, which generally are $<8 \mathrm{~m}$ tall (de Castro and Kauffman 1998). Many species of arboreal ants in the high forest canopy rarely descend to the forest floor (Camargo and Oliveira 2012) and thus depend on lianas for access to resources in neighboring tree crowns (Yanoviak 2015). This likely is not the case in cerrado habitat, where the shorter trees and well-lit understory impose relatively minimal costs to ant movement among trees via the ground. Additionally, for ants living on the forest floor, the relative physical complexity of leaf litter affects ant assemblage structure (Yanoviak and Kaspari 2000) and can facilitate coexistence by reducing discovery rates of food sources by dominant ant species (Sarty et al. 2006, Gibb and Parr 2010). In contrast, the results of this study indicate that connective structures promote ant diversity in the forest canopy by facilitating access to dispersed resources.

Although nest site additions did not affect within-tree ant species richness or composition, the results of the nest addition experiment suggest that lianas increase the availability of ant nest sites in the forest canopy (i.e., artificial nests were more frequently occupied in trees without lianas). This result is similar to previous work demonstrating that artificial nest occupancy is higher in structurally simple, low-shade coffee plantations (Philpott and Foster 2005). Nest expansion by polydomous resident ants likely precluded the establishment of new, nonresident ant species, similar to the findings of Powell et al. (2011). Collectively, these results highlight that although nest site resources provided by lianas are important to individual ant colony expansion, other factors, such as tree crown connectivity (Yanoviak 2015, Adams et al. 2017) or species interactions (Blüthgen and Stork 2007, Camarota et al. 2016), also significantly influence arboreal ant community structure.

Liana abundance is increasing in the BCNM (Ingwell et al. 2010, Schnitzer 2012, Schnitzer 2015), and will likely affect arboreal ant communities over the long term (Yanoviak 2015). Specifically, local arboreal ant species richness should increase when lianas are present. However, the results of this study suggest that overall $\beta$-diversity will not decrease, as would be expected by connecting normally discontinuous habitats like lakes (Rahel 2007). Additional experiments are needed to uncover the relative importance of other liana-based resources (e.g., extrafloral nectar; Blüthgen and Fiedler 2002) in shaping ant community structure, and to test the efficacy of different artificial nest designs (Powell et al. 2011, Yanoviak 2015). Given the complexities of tropical rainforest canopies, more large-scale experimental manipulations like those used in this study are needed to uncover the mechanisms driving patterns of local diversity.

\section{ACKNOWLEDGments}

Marilyn Feil, Dana Frederick, Evan Gora, Rachel Wells, and Amanda Winters assisted with fieldwork. John Longino, William MacKay, and Phillip Ward confirmed ant species identities. Greg Asner, Robin Martin, and S. Joseph Wright provided location information for D. oleifera trees on Barro Colorado Island. Comments from Nico Blüthgen, Chloé Debyser, Evan Gora, David Holway, Riley Kneale, Daniella Prince, Alyssa Stark, Rachel Wells, and an anonymous reviewer improved the manuscript. Riley Kneale created the project design figures. We thank Oris Acevedo, Melissa Cano, Belkys Jimenez, and the staff of the Smithsonian Tropical Research Institute for logistical support in 
Panama. This work was supported by a Carl C. Cornett Entomology Endowment grant to BJA, National Science Foundation (NSF) grant DEB-1252614 to SPY, and NSF grants DEB0845071, DEB-1019436, and DEB-1822473 to SAS.

\section{Literature Cited}

Adams, B. J., S. A. Schnitzer, and S. P. Yanoviak. 2017. Trees as islands: canopy ant species richness increases with the size of liana-free trees in a Neotropical forest. Ecography 40:1067-1075.

Agrawal, A. A., D. D. Ackerly, F. Adler, A. E. Arnold, C. Cáceres, D. F. Doak, E. Post, P. J. Hudson, J. Maron, and K. A. Mooney. 2007. Filling key gaps in population and community ecology. Frontiers in Ecology and the Environment $5: 145-152$.

Anderson, M., R. Gorley, and K. Clarke. 2008. PERMANOVA+ for Primer. Primer-E, Plymouth, UK.

Anderson, M. J., T. O. Crist, J. M. Chase, M. Vellend, B. D. Inouye, A. L. Freestone, N. J. Sanders, H. V. Cornell, L. S. Comita, and K. F. Davies. 2011. Navigating the multiple meanings of $\beta$ diversity: a roadmap for the practicing ecologist. Ecology Letters 14:19-28.

Beckers, R., S. Goss., J.-L. Deneubourg, and J.-M. Pasteels. 1989. Colony size, communication and ant foraging strategy. Psyche: A Journal of Entomology 96:239-256.

Bennett, A. F. 1999. Linkages in the landscape: the role of corridors and connectivity in wildlife conservation. IUCN, Gland, Switzerland.

Blüthgen, N., and K. Fiedler. 2002. Interactions between weaver ants Oecophylla smaragdina, homopterans, trees and lianas in an Australian rain forest canopy. Journal of Animal Ecology 71:793-801.

Blüthgen, N., and N. E. Stork. 2007. Ant mosaics in a tropical rainforest in Australia and elsewhere: a critical review. Austral Ecology 32:93-104.

Bolker, B. M., M. E. Brooks, C. J. Clark, S. W. Geange, J. R. Poulsen, M. H. H. Stevens, and J. S. S. White. 2009. Generalized linear mixed models: a practical guide for ecology and evolution. Trends in Ecology and Evolution 24:127-135.

Camargo, R. X., and P. S. Oliveira. 2012. Natural history of the Neotropical arboreal ant, Odontomachus hastatus: nest sites, foraging schedule, and diet. Journal of Insect Science 12:48.

Camarota, F., S. Powell, A. S. Melo, G. Priest, R. J. Marquis, and H. L. Vasconcelos. 2016. Co-occurrence patterns in a diverse arboreal ant community are explained more by competition than habitat requirements. Ecology and Evolution 6:8907-8918

Clarke, K. R., and R. N. Gorley. 2006. PRIMER V6: user manual-tutorial. Plymouth Marine Laboratory, Plymouth, UK.

Colwell, R. K., A. Chao, N. J. Gotelli, S.-Y. Lin, C. X. Mao, R. L. Chazdon, and J. T. Longino. 2012. Models and estimators linking individual-based and sample-based rarefaction, extrapolation and comparison of assemblages. Journal of Plant Ecology 5:3-21.

Condit, R. 1995. Research in large, long-term tropical forest plots. Trends in Ecology and Evolution 10:18-22.

Davidson, D. W., J. T. Longino, and R. R. Snelling. 1988. Pruning of host plant neighbors by ants: an experimental approach. Ecology 69:801-808.

Davidson, D. W., S. C. Cook, R. R. Snelling, and T. H. Chua. 2003. Explaining the abundance of ants in lowland tropical rainforest canopies. Science 300:969-972.

de Cáceres, M., P. Legendre, and M. Moretti. 2010. Improving indicator species analysis by combining groups of sites. Oikos 119:1674-1684. de Castro, E. A., and J. B. Kauffman. 1998. Ecosystem structure in the Brazilian Cerrado: a vegetation gradient of aboveground biomass, root mass and consumption by fire. Journal of Tropical Ecology 14:263-283.

Emmons, L., and A. H. Gentry. 1983. Tropical forest structure and the distribution of gliding and prehensile-tailed vertebrates. American Naturalist 121:513-524.

Ewers, R. M., et al. 2011. A large-scale forest fragmentation experiment: the Stability of Altered Forest Ecosystems Project. Philosophical Transactions of the Royal Society B, 366:3292-3302.

Fahrig, L. 2003. Effects of habitat fragmentation on biodiversity. Annual Review of Ecology, Evolution, and Systematics 34:487-515.

Fewell, J. H., J. F. Harrison, J. R. Lighton, and M. D. Breed. 1996. Foraging energetics of the ant, Paraponera clavata. Oecologia 105:419-427.

Frederickson, M. E. 2006. The reproductive phenology of an Amazonian ant species reflects the seasonal availability of its nest sites. Oecologia 149:418-427.

Garcia-Leon, M. M., L. Martinez-Izquierdo, J. S. Powers, and S. A. Schnitzer. 2018. Lianas reduce community-level canopy tree reproduction in a Panamanian forest. Journal of Ecology 106:737-745.

Gibb, H., and C. Parr. 2010. How does habitat complexity affect ant foraging success? A test using functional measures on three continents. Oecologia 164:1061-1073.

Gonzalez, A., J. H. Lawton, F. S. Gilbert, T. M. Blackburn, and I. Evans-Freke. 1998. Metapopulation dynamics, abundance, and distribution in a microecosystem. Science 281:2045-2047.

Gora, E. M., R. C. Kneale, M. Larjavaara, and H. C. MullerLandau. 2019. Dead wood necromass in a moist tropical forest: stocks, fluxes, and spatiotemporal variability. Ecosystems. http://dx.doi.org/10.1007/s10021-019-00341-5

Gotelli, N. J., A. M. Ellison, R. R. Dunn, and N. J. Sanders. 2011. Counting ants (Hymenoptera: Formicidae): biodiversity sampling and statistical analysis for myrmecologists. Myrmecological News 15:13-19.

Hanski, I., and M. Gilpin. 1991. Metapopulation dynamics: brief history and conceptual domain. Biological Journal of the Linnean Society 42:3-16.

Huffaker, C. B. 1958. Experimental studies on predation: dispersion factors and predator--prey oscillations. Hilgardia 27:343-383.

Ingwell, L. L., S. Joseph Wright, K. K. Becklund, S. P. Hubbell, and S. A. Schnitzer. 2010. The impact of lianas on 10 years of tree growth and mortality on Barro Colorado Island, Panama. Journal of Ecology 98:879-887.

Kaspari, M., N. A. Clay, J. Lucas, S. P. Yanoviak, and A. Kay. 2015. Thermal adaptation generates a diversity of thermal limits in a rainforest ant community. Global Change Biology 21:1092-1102.

Laurance, W. F., S. G. Laurance, L. V. Ferreira, J. M. Rankinde Merona, C. Gascon, and T. E. Lovejoy. 1997. Biomass collapse in Amazonian forest fragments. Science 278:1117-1118.

Leigh, E. G., A. S. Rand, and D. M. Windsor, editors. 1996. The ecology of a tropical forest: seasonal rhythms and longterm changes. Smithsonian Press, Washington, D.C., USA.

Levins, R., M. L. Pressick, and H. Heatwole. 1973. Coexistence patterns in insular ants: in which it is shown that ants travel a lot from island to island, and what they do when they get there. American Scientist 61:463-472.

Longino, J. T. 2007. A taxonomic review of the genus Azteca (Hymenoptera: Formicidae) in Costa Rica and a global revision of the aurita group. Zootaxa 1491:1-63.

MacArthur, R. H., and J. W. MacArthur. 1961. On bird species diversity. Ecology 42:594-598. 
MacArthur, R. H., and E. O. Wilson. 1967. The theory of island biogeography. Princeton University Press, Princeton, New Jersey, USA.

Martínez-Izquierdo, L., M. M. García, J. S. Powers, and S. A. Schnitzer. 2016. Lianas suppress seedling growth and survival of 14 tree species in a Panamanian tropical forest. Ecology 97:215-224.

Metaxas, A., and R. E. Scheibling. 1993. Community structure and organization of tidepools. Marine ecology progress series. Oldendorf 98:187-198.

Ng, F. S. P. 1977. Shyness in trees. Nature Malaysiana 2:35-37.

O'Brien, S. T., S. P. Hubbell, P. Spiro, R. Condit, and R. B. Foster. 1995. Diameter, height, crown, and age relationship in eight neotropical tree species. Ecology 76:1926-1939.

Patiño, J., C. Gómez-Rodríguez, A. Pupo-Correia, M. Sequeira, and A. Vanderpoorten. 2018. Trees as habitat islands: temporal variation in alpha and beta diversity in epiphytic laurel forest bryophyte communities. Journal of Biogeography 45:1727-1738.

Pérez-Salicrup, D. R., V. L. Sork, and F. E. Putz. 2001. Lianas and trees in a liana forest of Amazonian Bolivia. Biotropica 33:34-47.

Perry, D. R. 1978. A method of access into the crowns of emergent and canopy trees. Biotropica 10:155-157.

Phillips, O. L., R. Vásquez Martínez, A. Monteagudo Mendoza, T. R. Baker, and P. Núñez Vargas. 2005. Large lianas as hyperdynamic elements of the tropical forest canopy. Ecology 86:1250-1258

Philpott, S. M. 2010. A canopy dominant ant affects twig-nesting ant assembly in coffee agroecosystems. Oikos 119:1954-1960.

Philpott, S. M., and P. F. Foster. 2005. Nest-site limitation in coffee agroecosystems: artificial nests maintain diversity of arboreal ants. Ecological Applications 15:1478-1485.

Powell, S., A. N. Costa, C. T. Lopes, and H. L. Vasconcelos. 2011. Canopy connectivity and the availability of diverse nesting resources affect species coexistence in arboreal ants. Journal of Animal Ecology 80:352-360.

Preston, F. W. 1962. The canonical distribution of commonness and rarity: part I. Ecology 43:185-215.

Putz, F. E. 1984a. How trees avoid and shed lianas. Biotropica 16:19-23.

Putz, F. E. 1984b. The natural history of lianas on Barro Colorado Island, Panama. Ecology 65:1713-1724

Putz, F. E., G. G. Parker, and R. M. Archibald. 1984. Mechanical abrasion and intercrown spacing. American Midland Naturalist 112:24-28.

R Core Team. 2018. R: a language and environment for statistical computing. R Foundation for Statistical Computing. Vienna, Austria. www.r-project.org

Rahel, F. J. 2007. Biogeographic barriers, connectivity and homogenization of freshwater faunas: it's a small world after all. Freshwater Biology 52:696-710.

Reid, J. P., S. A. Schnitzer, and J. S. Powers. 2015. Short and long-term soil moisture effects of liana removal in a seasonally moist tropical forest. PLoS ONE 10:e0141891.

Ribas, C. R., J. H. Schoereder, M. Pic, and S. M. Soares. 2003. Tree heterogeneity, resource availability, and larger scale processes regulating arboreal ant species richness. Austral Ecology 28:305-314.

Rico-Gray, V., and P. S. Oliveira. 2007. The ecology and evolution of ant-plant interactions. University of Chicago Press, Chicago, Illinois, USA.

Rodriguez-Ronderos, M. E., G. Bohrer, A. Sanchez-Azofeifa, J. S. Powers, and S. A. Schnitzer. 2016. Contribution of lianas to plant area index and canopy structure in a Panamanian forest. Ecology 97:3271-3277.

Sarty, M., K. L. Abbott, and P. J. Lester. 2006. Habitat complexity facilitates coexistence in a tropical ant community. Oecologia 149:465-473.

Schnitzer, S. A. 2015. Increasing liana abundance and biomass in neotropical forests: causes and consequences. Pages 451-464 in S. A. Schnitzer, F. Bongers, R. Burnham, and F. E. Putz, editors. The ecology of lianas. Wiley-Blackwell, Chichester, UK.

Schnitzer, S. A., et al. 2012. Liana abundance, diversity, and distribution on Barro Colorado Island, Panama. PLoS ONE 7:e52114.

Shulman, M. J. 1984. Resource limitation and recruitment patterns in a coral reef fish assemblage. Journal of Experimental Marine Biology and Ecology 74:85-109.

Southwood, T. R. E., and C. E. J. Kennedy. 1983. Trees as islands. Oikos 41:359-371.

Stark, A. Y., B. J. Adams, J. L. Fredley, and S. P. Yanoviak. 2017. Out on a limb: thermal microenvironments in the tropical forest canopy and their relevance to ants. Journal of Thermal Biology 69:32-38.

Tanaka, H. O., S. Yamane, and T. Itioka. 2010. Within-tree distribution of nest sites and foraging areas of ants on canopy trees in a tropical rainforest in Borneo. Population Ecology $52: 147-157$

Taylor, P. D., L. Fahrig, K. Henein, and G. Merriam. 1993. Connectivity is a vital element of landscape structure. Oikos 68:571-573

Tewksbury, J. J., D. J. Levey, N. M. Haddad, S. Sargent, J. L. Orrock, A. Weldon, B. J. Danielson, J. Brinkerhoff, E. I. Damschen, and P. Townsend. 2002. Corridors affect plants, animals, and their interactions in fragmented landscapes. Proceedings of the National Academy of Sciences USA 99:12923-12926.

Tews, J., U. Brose, V. Grimm, K. Tielbörger, M. C. Wichmann, M. Schwager, and F. Jeltsch. 2004. Animal species diversity driven by habitat heterogeneity/diversity: the importance of keystone structures. Journal of Biogeography 31:79-92.

Tilman, D. 1982. Resource competition and community structure. Princeton University Press, Princeton, New Jersey, USA.

Tilman, D., and S. Pacala. 1993. The maintenance of species richness in plant communities. Pages 13-25 in R. E. Ricklefs and D. Schluter, editors. Species diversity in ecological communities. University of Chicago Press, Chicago, Illinois, USA.

van der Heijden, G. M., J. S. Powers, and S. A. Schnitzer. 2015. Lianas reduce carbon accumulation and storage in tropical forests. Proceedings of the National Academy of Sciences USA 112:13267-13271

Ward, P. S. 1989. Systematic studies on pseudomyrmecine ants: revision of the Pseudomyrmex oculatus and P. subtilissimus species groups, with taxonomic comments on other species. Quaestiones Entomologicae 25:393-468.

Yanoviak, S. P. 2015. Effects of lianas on canopy arthropod community structure. Pages 345-361 in S. A. Schnitzer, F. Bongers, R. Burnham, and F. E. Putz, editors. The ecology of lianas. Wiley-Blackwell, Chichester, UK.

Yanoviak, S. P., and M. Kaspari. 2000. Community structure and the habitat templet: ants in the tropical forest canopy and litter. Oikos 89:259-266.

Yanoviak, S. P., and S. A. Schnitzer. 2013. Functional roles of lianas for forest canopy animals. Pages 209-214 in M. Lowman, S. Devy, and T. Ganesh, editors. Treetops at risk: challenges of global forest canopies. Springer, New York, New York, USA. 


\section{SUPPORTING INFORMATION}

Additional supporting information may be found in the online version of this article at http://onlinelibrary.wiley.com/doi/ 10.1002/ecy.2673/suppinfo

\section{Data Availability}

Data are available from the Dryad Digital Repository: https://doi.org/10.5061/dryad.302bd95 